\title{
Impact of aerosols and clouds on decadal trends in all-sky solar radiation over the Netherlands (1966-2015)
}

\author{
Reinout Boers, Theo Brandsma, and A. Pier Siebesma \\ KNMI, De Bilt, P.O. Box 201, The Netherlands \\ Correspondence to: Reinout Boers (reinout.boers@knmi.nl)
}

Received: 31 January 2017 - Discussion started: 27 February 2017

Revised: 15 May 2017 - Accepted: 16 May 2017 - Published: 4 July 2017

\begin{abstract}
A 50-year hourly data set of global shortwave radiation, cloudiness and visibility over the Netherlands was used to quantify the contribution of aerosols and clouds to the trend in yearly-averaged all-sky radiation $\left(1.81 \pm 1.07 \mathrm{~W} \mathrm{~m}^{-2}\right.$ decade $\left.^{-1}\right)$. Yearly-averaged clearsky and cloud-base radiation data show large year-to-year fluctuations caused by yearly changes in the occurrence of clear and cloudy periods and cannot be used for trend analysis. Therefore, proxy clear-sky and cloud-base radiations were computed. In a proxy analysis hourly radiation data falling within a fractional cloudiness value are fitted by monotonic increasing functions of solar zenith angle and summed over all zenith angles occurring in a single year to produce an average. Stable trends can then be computed from the proxy radiation data. A functional expression is derived whereby the trend in proxy all-sky radiation is a linear combination of trends in fractional cloudiness, proxy clearsky radiation and proxy cloud-base radiation. Trends (per decade) in fractional cloudiness, proxy clear-sky and proxy cloud-base radiation were, respectively, $0.0097 \pm 0.0062$, $2.78 \pm 0.50$ and $3.43 \pm 1.17 \mathrm{~W} \mathrm{~m}^{-2}$. To add up to the allsky radiation the three trends have weight factors, namely the difference between the mean cloud-base and clear-sky radiation, the clear-sky fraction and the fractional cloudiness, respectively. Our analysis clearly demonstrates that all three components contribute significantly to the observed trend in all-sky radiation. Radiative transfer calculations using the aerosol optical thickness derived from visibility observations indicate that aerosol-radiation interaction (ARI) is a strong candidate to explain the upward trend in the clear-sky radiation. Aerosol-cloud interaction (ACI) may have some impact on cloud-base radiation, but it is suggested that decadal
\end{abstract}

changes in cloud thickness and synoptic-scale changes in cloud amount also play an important role.

\section{Introduction}

Aerosols and clouds impact the solar radiation reaching the surface by radiative absorption and scattering. Although there have been well-recorded trends in the all-sky radiation all over the globe it has been difficult to precisely attribute such trends to trends in either aerosols or clouds. Widespread reductions in all-sky radiation in the 1950-1970s ("dimming") have been followed by increases in later decades ("brightening"), especially in Europe (Wild et al., 2005; Wild, 2009). Indeed, a thorough evaluation of all-sky radiation data over Europe (Sanchez-Lorenzo et al., 2015) shows conclusively the distinct dip during the 1970s flanked on either side by an earlier downward trend and a later upward trend. The later upward trends are thought to be the result of changes in aerosol content and/or to changes in fractional cloudiness.

One issue hampering the understanding of records of allsky radiation is that the impacts of aerosols and clouds need to be derived from a single record at observational sites where additional data, for instance from clouds, were often not present. This has led some investigators to group data into regions and rely either on cloud data from stations in the immediate surroundings or from satellites (or both) to supplement their radiation records (Norris and Wild, 2007). Even though good results on trends in clear-sky radiation can be obtained at sites where direct and solar radiation are recorded at the same time, such as Baseline Surface Radiation Network stations (Long and Ackermann, 2000; Long 
et al., 2009; Wild et al., 2005; Gan et al., 2009), most often an investigator will have to rely on single global radiation data records that are specific to the region of interest (such as Manara et al., 2016) or on data stored in the Global Energy Balance Archive (GEBA) archive. GEBA data can be used to good effect because of the fact that many stations have submitted data, but the peculiarities of the radiative signals typical to individual localities are invariably lost in the abundance of data. It is therefore of great importance that regional studies are carried out that record the changes in surface radiation in relation to atmospheric parameters that can influence such changes.

In the context of Europe there have been a considerable number of regional studies that focus on trends in global radiation and their attribution, such as in Germany (Liepert and Tegen, 2002; Liepert and Kukla, 1997; Liepert, 1997, 2002), in Germany and Switzerland combined (Ruckstuhl et al., 2008; Ruckstuhl and Norris, 2009; Ruckstuhl et al., 2010), in Estonia (Russak, 2009), in the general Baltic states (Ohvril et al., 2009), in Spain (Mateos et al., 2014), in Norway (Parding et al., 2014), northern Europe in general (Stjern et al., 2009) and in Italy (Manara et al., 2015). Even though there are regional differences, the summarized global or allsky radiation data from Europe combined (Sanchez-Lorenzo et al., 2015) display a minimum in 1984-1985 at the end of a "dimming" period with a subsequent return to higher values. The consensus about the decadal trends in global radiation hides a considerable discourse about the attribution of the radiation trends. Of the parameters of interest when investigating the trends in all-sky radiation, namely clear-sky radiation, cloudy-sky radiation and fractional cloudiness, the first two have been difficult to isolate from data and were addressed in only a few studies (Wild, 2010). However, an increasing number of studies indicate that there are good reasons to believe that aerosol-radiation interaction (ARI) is responsible for the rise in all-sky radiation after 1985 (e.g. Philipona et al., 2009; Manara et al., 2016; Ruckstuhl et al., 2008) although the timing of the minimum or intensity cannot be simulated very well using current aerosol emission inventories (Ruckstuhl and Norris, 2009; Liepert and Tegen, 2002; Romanou et al., 2007; Turnstock et al., 2015). Concerning the influence of clouds, the situation continues to be elusive. While it is obvious that clouds are important, the difficulty here is that there are several factors that control their impact. For example there are considerable regional differences in fractional cloudiness (Norris, 2005): fractional cloudiness is constant in northern Europe (Parding et al., 2014) and in Germany before 1997 (Liepert, 1997), well after the minimum in global radiation in 1984, and has declined in the period after 1997 in Switzerland and Germany, at least until 2010 (Ruckstuhl et al., 2010). Furthermore, cloud optical thickness changes can be the result of changes in microphysics or cloud thickness and current observations are not able to separate the two effects. Nevertheless, modelling and observation studies by Romanou et al. (2007), Ruckstuhl and
Norris (2009), Chiacchio and Wild (2010), Liepert (1997), Liepert and Kukla (1997), Long et al. (2009) and Augustine and Dutton (2009) suggest a definite but mixed role for clouds impacting the trend in all-sky radiation.

Attribution studies using only surface-based observations must rely on supplemental data, namely those of clouds (predominantly fractional cloudiness) and aerosols. Also, data on fractional cloudiness need to be collected simultaneously with radiation data. Up to the mid-1990s clouds were observed by human observers but since then the role of the observers is taken over by ceilometers. Apart from occasional sun photometer records (Ruckstuhl et al. (2008), data on aerosol are often unavailable. However, recent studies by $\mathrm{Wu}$ et al. (2014) and Boers et al. (2015) have shown that it is possible to retrieve useful aerosol optical thickness data from surface visibility records. The principal idea behind both studies is almost 50 years old (Eltermann, 1970; Kriebel, 1978; Peterson and Fee, 1981; revived by the work of Wang et al., 2009) and asserts that clear-sky optical thickness is most often caused by aerosols residing in the planetary boundary layer, which can be characterized by the optical extinction at $550 \mathrm{~nm}$. This parameter is by definition proportional to the inverse of atmospheric horizontal visibility, which in turn is a quantity abundantly observed over at least 50 years, often together with observations of radiation.

Because of the importance attached to potential attribution of observed regional trends in all-sky radiation to aerosols and/or clouds, we analyse hourly records of radiation, cloudiness and visibility data at five climate stations in the Netherlands for the 50-year period of 1966-2015. The two aims of this study are (a) to quantify the decomposition of the allsky flux into its contributing components and compute the decadal trends in the components and (b) to discern the relative importance of aerosols and clouds in shaping the observed trends.

The remainder of this paper is organized as follows: Sect. 2 describes briefly the theory and analysis procedures to obtain clear- and cloudy-sky signals from the all-sky data. The procedures combine radiation and cloud coverage data. Equations describe the manner in which the all-sky radiation is explicitly dependent upon fractional cloudiness, clear-sky radiation and radiation emanating at cloud base. The equations are based on elementary principles but we believe that this is the first time that these dependencies are explicitly quantified, although the work by Liepert (1997), Liepert (2002), Liepert and Kukla (2002) and Ruckstuhl et al. (2010) contain elements similar to our work. A full derivation of the equations is presented in the Appendix.

In Sect. 3 the data analysis is discussed: all metadata for all stations recorded between the late 1950s and today were examined in order to better understand the impact of any changes in instruments and location and calibrations on the data. Homogeneity tests were performed to discern any possible discontinuities in the data and to understand whether all climate stations indeed belonged to the same climatological 
regime. Attention is also given to a break in the cloud observations that occurred in 2002 with the transition from the human observer to the ceilometer. Section 4 show the results. The relative influence of clear-sky radiation, cloudy-sky radiation and fractional cloudiness on the all-sky radiation are shown. Also, the relative merits of ARI and aerosol-cloud interaction (ACI) in influencing the all-sky radiation are discussed.

Section 5 concludes this paper with discussion and conclusions.

\section{Method}

\subsection{Radiation data, their proxies and trends}

An important aspect of this paper is to quantify the various radiative contributions to the all-sky radiation. It is shown in this subsection that there is an elegant way to do so while invoking a minimum set of assumptions. The radiative contributions arise from skies under clear, partly cloudy or overcast sky conditions. The presence of cloud cover which is recorded simultaneously with the radiation assures that it is possible to quantify these different contributions. Cloud cover is normally recorded in oktas $(0-8)$ so that nine different contributions to the radiation can be identified, which together build up the all-sky radiation.

For each okta value it will be assumed that the observed radiation is a linear combination of clear-sky radiation and radiation emanating from cloud base, each with cloud fraction weight factors that correspond to the okta value at hand. The result is an equation which casts the all-sky radiation as a function of only three components: (1) the clear-sky radiation, (2) the cloud-base radiation and (3) the fractional cloudiness. Long-term changes in cloud type could perhaps affect cloud optical properties (liquid water versus ice water) but their influence on trends is unknown and not studied here. The process to calculate the three components is then repeated for each year in the period 1966-2015, resulting in three time series. The method thus assures that the relative importance of clear-sky radiation, cloud-base radiation and fractional cloudiness to the trend in all-sky radiation can be quantified.

Unfortunately, as has been shown before (Ruckstuhl et al., 2010) the analysis of trends using real-data time series is prone to large errors as periods of cloudy and clear sky occur at random times throughout the year. Thus, the year-to-year variations in averages are mostly the result of differences in the selection of solar zenith angles used in constructing yearly averages. In the study of decadal variability that may be attributable to physical causes this is an undesirable side effect so that an alternative method needs to be applied in the trend analysis.

The method we applied is coined an analysis of "proxies". We make use of the fact that for each okta value the observed radiation data can be fitted by a monotonically increasing function of solar zenith angle. The line fit is next evaluated at all hourly solar zenith angles occurring in a single year and averaged. The average proxy radiation data that are thus obtained give a much more stable set of values from which (decadal) trends can be calculated.

If $S_{k}$ is the yearly-averaged all-sky radiation (an observable), then $S_{\mathrm{p} k}$ is the yearly-averaged all-sky proxy radiation in year $y_{k}$. It can be shown that

$S_{\mathrm{p} k}=S_{\mathrm{p}, c_{0} k}\left(1-c_{k}\right)+c_{k} S_{\mathrm{p}, \text { cloud }, k}$,

where $S_{\mathrm{p}, c_{0}, k}$ is the yearly-averaged clear-sky proxy radiation, $c_{k}$ is the yearly-averaged fractional cloudiness and

$$
S_{\mathrm{p}, \text { cloud }, k}=\frac{\sum_{j=1}^{8} f_{k}\left(c_{j}\right) c_{j} S_{\mathrm{p}, \mathrm{cb}, c_{j}, k}}{\sum_{j=1}^{8} f_{k}\left(c_{j}\right) c_{j}},
$$

with $f_{k}\left(c_{j}\right)$ the fractional occurrence of okta $j$ in a given year $k, c_{j}$ the fractional cloudiness corresponding to okta $j$ (see further description of this procedure in Sect. 3.4) and $S_{\mathrm{p}, \mathrm{cb}, c_{j}, k}$ the cloud-base proxy radiation occurring at okta value $j$. A full derivation to arrive at Eq. (1) is given in the Appendix.

In summary, the all-sky proxy radiation can be expressed as a linear combination of the clear-sky proxy and the cloudbase proxy radiation, each weighted by their yearly mean coverage. Note that the real all-sky radiation $\left(S_{k}\right)$ and the proxy all-sky radiation $\left(S_{\mathrm{p} k}\right)$ are different, although they are of course quite close in value. $S_{k}$ is observable, while $S_{\mathrm{p} k}$ is derived from Eq. (1) after its components on the right side are first evaluated. However, an a posteriori comparison between the two has shown that they agree with each other better with a better than $5 \%$ margin.

Using Eq. (1) trends can be calculated using the deviation from the averages over 5 decades:

$$
\begin{aligned}
S_{\mathrm{p} k}^{\prime} & =c_{k}^{\prime}\left(\overline{S_{\mathrm{p}, \text { cloud }}}-\overline{S_{\mathrm{p}, c_{0}}}\right)+(1-\bar{c}) S_{\mathrm{p}, c_{0}, k}^{\prime}+\bar{c} S_{\mathrm{p}, \text { cloud }, k}^{\prime} \\
& +c_{k}^{\prime}\left(S_{\text {cloud }, k}^{\prime}-S_{\mathrm{p}, c_{0}, k}^{\prime}\right),
\end{aligned}
$$

where $S_{\mathrm{p} k}^{\prime}$ is yearly deviation of the average over the 5 decades of the all-sky proxy radiation; $c_{k}^{\prime}$ is the yearly deviation of the average over the 5 decades of the fractional cloud cover; $\bar{c}$ is the average over the 5 decades of the fractional cloudiness; $S_{\mathrm{p}, c_{0}, k}^{\prime}$ is the yearly deviation of the average over the 5 decades of the clear-sky proxy radiation; $\overline{S_{\mathrm{p}, c_{0}}}$ is the average over the 5 decades of the clear-sky proxy radiation; $S_{\mathrm{p}, \text { cloud }, k}^{\prime}$ is the yearly deviation of the average over the 5 decades of the cloud-base proxy radiation; $\overline{S_{\mathrm{p}, \text { cloud }}}$ is the average over the 5 decades of the cloud-base proxy radiation.

The derivation of Eq. (3) is given in the Appendix.

Equation (3) is the desired result for the analysis of trends. The first component on the right-hand side represents perturbations/trends in fractional cloudiness multiplied by the 
difference in cloud-base and clear-sky radiation, which is negative. Therefore a positive trend in fractional cloudiness will impact as a negative trend component in building up the all-sky radiation. The second term represents the clearsky perturbations/trends weighted by the average occurrence of clear skies (in our case approximately 0.32). The third term represents the perturbations/trends in cloud-base radiation weighted by the fractional cloud cover (in our case approximately 0.68 ). The fourth term is a cross-correlation term which in practice can be neglected.

Equation (3) explains to a large extent the difficulties in attribution studies of the all-sky radiation. Not only are the trends in fractional cloudiness, clear-sky and cloud-base radiation important, but their relative weight as determined by the mean fractional cloudiness and the difference between the mean clear-sky and cloud-base radiation are as well. In other words, there are a total of five different factors contributing to the trend in all-sky radiation. For example, when the mean cloud fraction is large, as in north-western Europe, the impact of the trend in clear-sky radiation on the trend in all-sky radiation will be relatively modest in comparison to the impact of trend in cloud-base radiation. The latter would be weighted by a factor of 2 more than the trend in clear-sky radiation $(0.32$ versus 0.68$)$.

Tests of trends will be performed using the standard Mann-Kendall (Kendall, 1975) non-parametric test often used in this type of analysis (see e.g. Long et al., 2009) after the time series was first decorrelated. The uncertainty value attached to the trend is a test of significance indicating the $95 \%$ confidence interval of the calculated slope line. The uncertainties in trend are due to two factors, namely uncertainties in yearly-averaged values of $S_{\mathrm{p}}$ as a result of uncertainties in fitting constants in Eq. (A19) (see Appendix for details) and the natural variability of a multi-year or even decadal origin. Thus the stated uncertainty in output trend is a mix of both factors.

\subsection{Retrieval of aerosol optical thickness}

Once the method to decompose the all-sky radiation into its clear-sky and cloudy-sky (proxy) components has been applied and a trend analysis is performed, then it is our goal to seek an answer to the question of which processes might be responsible for their long-term change. Although possible long-term changes in the synoptic conditions are a conceivable influence, an obvious candidate for exploration of cause is the changing aerosol content of the atmosphere. Aerosol content/concentration was not directly observed but visibility was recorded throughout the period from which aerosol optical thickness was derived.

Aerosol optical thickness is the single most controlling factor in changing clear-sky radiation. A radiative transfer model is used here to calculate the clear-sky radiation as a function of the changing optical thickness. The output was compared to the observed clear-sky radiation. The process whereby aerosol can directly affect clear-sky radiation is denoted as the aerosol direct effect or, using a term used in the IPCC (IPCC, 2013) report, the ARI.

Aerosols can also affect the microphysical structure of clouds, which in turn affects its radiative structure, a process which is commonly denoted as the aerosol indirect effect, or ACI (as using the terminology of IPCC, 2013).

The aerosol optical thickness of the atmosphere $\left(\tau_{\mathrm{a}}\right)$ is a function of aerosol extinction $\left(\sigma_{\mathrm{a}}\right)$ integrated over the depth of the atmosphere

$\tau_{\mathrm{a}}=\int_{0}^{h} \sigma_{\mathrm{a}} \mathrm{d} z=\int_{0}^{h} \int_{r} Q n(r) r^{2} \mathrm{~d} r \mathrm{~d} z$,

where $Q$ is the scattering efficiency and can be obtained from Mie calculations. The parameter $n(r)$ is the density of the size distribution and $r$ is the radius of the particle. The vertical integration over height $z$ is over the depth of the atmosphere $(h)$ and this yields using the mean value theorem:

$\tau_{\mathrm{a}} \sim \sigma_{\mathrm{a}, \text { mean }} H=Q_{\text {mean }} N_{\mathrm{a}} H R^{2}$.

Here $N_{\mathrm{a}}$ is the concentration of aerosols, $R$ is the mean size of the aerosol particles and $H$ is a scaling depth proportional to the depth of the planetary boundary layer. The proportionality factor includes all vertical variations in aerosol, size distribution and optical properties. Aerosol extinction can be approximated as (Eltermann, 1970; Kriebel, 1978, Peterson and Fee, 1981; Wang et al., 2009)

$\sigma_{\mathrm{a}, \text { mean }}=\frac{-\log _{e}(0.05)}{\text { Visibility }}$.

Visibility is a measurable quantity and it provides a means to compute aerosol optical thickness at hourly intervals from standard weather station observations. This procedure has been used to obtain decadal time series of the aerosol optical thickness over the Netherlands and China (Boers et al., 2015; Wu et al., 2014). We examined the European Centre for Medium-Range Weather Forecasts reanalysis (ERA-Interim) data (Dee et al., 2011) for changes in the planetary boundary layer depth. No indications for changes were found in the course of 50 years and a value of $1000 \mathrm{~m}$ was used to reflect conditions over the Netherlands.

\subsection{Radiative transfer calculations}

Variations or trends in solar radiation under cloudless conditions are mostly caused by variations in the optical properties and concentrations of aerosols, the ARI. The principle aim here is to assess whether the variations in optical properties can explain the observed variations in solar radiation. For this purpose, we used a simple radiation transfer model based on the delta-Eddington two-stream approach, as added complexity in radiative transfer models will not increase the confidence in our results (Boers and Mitchell, 1994). 
For model calculations, the parameters affecting the radiation are the aerosol optical thickness, single scattering albedo, asymmetry parameter and Ångstrøm parameter. Of these four parameters the first two are the most important and only the first one can be obtained from observations. It was attempted to derive the single scattering albedo and its time variation from the aerosol composition in the Netherlands (Boers et al., 2015) but its precise quantification remains elusive due to its uncertain dependence on aerosol composition, wavelength, aerosol hygroscopicity and relative humidity. Thus a constant value of 0.90 was used instead. The results of Boers et al. (2015) indicate that a considerable portion of the reduction in aerosol optical thickness or potential solar brightening can be attributed to the reduction of sulfate aerosols after the 1980s. Even though the nitrate values did increase over the same time, their increases cannot completely counterbalance the decreasing sulfate concentrations. The asymmetry parameter and the Ångstrøm parameter are set to 0.69 and 1.5 , respectively, to reflect typical aerosol values derived for the Netherlands (Boers et al., 2015).

\subsection{Solar radiation and aerosol-cloud interaction}

Variations or trends in solar radiation emanating from the action of clouds are mostly caused by variations in the cloud fractional coverage and by variations in the optical properties and concentrations of droplets or ice. The two main hypotheses for ACI to operate on cloud properties are formulated below as hypotheses 1 and 2, in the remainder of this paper referred to as ACI-I and ACI-II, respectively. ACI-I suggests that variations in cloud optical properties are attributable to variations in aerosol concentration itself. A massive amount of literature has been devoted to this subject, but Twomey (1977) is the first one to describe this effect. It is based on a causal link between changes in aerosol concentration $\left(N_{\mathrm{a}}\right)$ and cloud droplet concentration $\left(N_{\mathrm{c}}\right)$. These two parameters are not necessarily linearly linked: as the amount of aerosol particles increases, it becomes more and more difficult to raise the supersaturation necessary to activate additional particles. Therefore, $N_{\mathrm{c}}$ and $N_{\mathrm{a}}$ are often related by means of a logarithmic function or a power law with exponent smaller than 1 (Jones et al., 1994; Gultepe and Isaac, 1995), e.g.

$N_{\mathrm{c}} \sim N_{\mathrm{a}}^{0.26}$.

Only a limited amount of aerosol particles will be activated to cloud droplets and incipient water droplets all compete for the same amount of water vapour as they grow. This means that the mean size of cloud droplets decreases as the number of cloud droplets increases. The consequence for the cloud optical thickness (Twomey, 1977) is that

$\tau_{\mathrm{c}, \mathrm{ACI}} \sim H_{\mathrm{c}} N_{\mathrm{c}}^{1 / 3}$.

Here $H_{\mathrm{c}}$ is the depth of the cloud and $\tau_{\mathrm{c}, \mathrm{ACI}}$ is the cloud optical thickness attributable to the aerosol-cloud interaction
(ACI-I). Thus, compared to Eq. (5) where the equivalent link between aerosol optical thickness and aerosol number concentration is described the dependence of cloud optical depth to number concentration is much weaker.

Combining Eqs. (7) and (8) with Eq. (5) we find

$\tau_{\mathrm{c}, \mathrm{ACI}} \sim \tau_{\mathrm{a}}^{0.26 / 3}$.

As the cloud optical thickness $\tau_{\mathrm{c}}$ (which is due to the ACI-I and other causes) can be obtained from inverting the cloudbase radiative fluxes and $\tau_{\mathrm{a}}$ can be obtained from Eqs. (7) and (8), the validity of the Eq. (9) can be studied.

ACI-II suggests that increasing $N_{\mathrm{c}}$ will result in suppression of precipitation so that cloud lifetime and cloud fraction is increased (Albrecht, 1989). In our analysis, cloud fraction is obtained in a straightforward manner by counting the hourly cloud data so that the hypothesis that changes in aerosol results in changes in cloud cover can be tested.

\section{Data analysis}

\subsection{Data sources}

We used quality-controlled time series of hourly data of surface radiation, cloudiness and visibility, which are standard output commonly available to the general public and submitted to the traditional climate data repositories. The surface radiation data consist of $12 \mathrm{~s}$ data for shortwave radiation instruments integrated over the hour. To be consistent with most publications on the subject of trends in radiation, the hourly average is taken and expressed in $\mathrm{W} \mathrm{m}^{-2}$. The visibility is recorded at the end of each hour, either by the Human Observer (until 2002) or taken from a present weather sensor (PWS, after 2002). The PWS detects the forward scattering of light emitted by a near-infrared light-emitting diode under an angle of $42^{\circ}$. Cloud cover is observed by the Human Observer until 2002 and represents the last 10 min of every hour. After 2002 it is observed by a vertically pointing ceilometer and represents the average of the last $30 \mathrm{~min}$ of the hour.

A serious concern is that conditional sampling was done on the radiation data in a situation where the observation that represents the condition (namely whether or not clouds are present) was not taken in exactly the same time interval as the observation (radiation) itself. Therefore the conditionally sampled data are an imperfect representation of the true situation. This is particularly true for rapidly changing cloudiness conditions. This issue cannot be rectified. However, in this paper exclusive use is made of yearly averages of conditionally sampled radiation data. For these data, the averaging procedure cancels out data with too much or too few clouds within the hour of the selected radiation data, so that the variability observed in the data will be simply enhanced random noise. 


\subsection{Metadata}

Table 1 presents the basic metadata of the five principal climate stations in the Netherlands together with the dates when the collection of radiation data started. The station metadata archive was analysed, from which it was apparent that initially the regular maintenance and understanding of instruments was inadequate. Typical problems that needed to be overcome were the build-up of moisture between the concentric glass half-domes, the removal of dust and bird droppings, the horizontal alignment of the instrument and the proper positioning of instruments with respect to shading obstacles such as (growing) trees.

Apart from these issues, insufficient (re)calibration of the instruments and irregular replacement/rotation of instruments from the instrument pool are the reason that the initial years of observation often yielded data of dubious quality. In the end it was decided to discard all data from the climate stations before the year 1966. The data from the station De Bilt are of acceptable quality from 1961 onwards, in particular since from that year onward radiation was measured by two radiometers that were placed side by side. However, these earlier data will not be used here because this would induce unacceptable weighting on this station of the radiation average in the 5-year period prior to the year 1966.

When proper calibration procedures were eventually in place, instruments were rotated from the instrument pool on a 12-15-month cycle out of KNMI, where calibration was done according to fixed procedures. Based on these procedures individual hourly observations were estimated to have a random (i.e. unbiased) uncertainty of $8 \%$. However, per year 8760 or 8784 are used to produce the average and with no bias in individual observations the uncertainty in the average is negligible in comparison to the trends in radiation to be shown below (see Sect. 4).

\subsection{Homogeneity test}

Even though some investigators have attempted with some success to homogenize and gap-fill their data (Manara et al., 2016) for a small region of the Netherlands with a few stations (in our case, five), such a homogenization procedure is unlikely to be successful. The reason is that it carries the risk of replacing real data with bogus data, which would weigh heavily on the few data time series available. Nevertheless it is instructive to apply a homogeneity test to understand differences between the time series.

The five radiation time series were analysed for statistical homogeneity using the Standard Normal Homogeneity Test (SNHT; Alexanderson, 1986). Instead of applying SNHT directly to each station series, we used relative testing. Relative testing removes the natural variation from a time series (while assuming that natural variation is about the same for all locations), which increases the probability of detecting statistically significant breaks. The SNHT was applied twice to each station series. In the first test each station series was subtracted by the mean of the four other station time series. In the second test each station series was subtracted by the other four station time series separately. The latter would reveal a break in the series. Note, however, that the results yield potential statistical breaks, not real ones.

The homogeneity testing was applied to the 1966-2015 period. The results indicate that De Bilt data are different from the others in the 1966-1975 period, though a possible inhomogeneity reveals itself only in two of the four relative series. From the metadata there is, however, no reason to doubt the quality of the series of De Bilt in this particular period. In fact of all five stations the instruments at the De Bilt observatory were probably maintained in the most optimum way. Also, the series of Eelde appears to be high relative to the other four stations for the 1966-1972 period, although again from the metadata there is no reason to judge the series of Eelde in this particular period as suspect. Eelde is the most north-easterly station in the Netherlands and data from this station were compared to the nearest German station with a long radiation time series (Norderney, 1967-2015). This comparison indicated that Eelde is homogeneous with Norderney, strongly suggesting that the relative high values of radiation at Eelde in the period 1966-1972 are indicative of real atmospheric variability rather than instrumental problems.

A similar homogeneity test was applied to the standard aerosol optical thickness output from the stations based on Eq. (6), which in turn are based on the visibility observations. No discontinuity was detected at the year 2002, indicating good adjustment procedures from Human Observer to instrument at the transition time. From these tests it emerges that the stations Vlissingen and De Bilt depart the most from the average. Furthermore, when all stations are compared, De Bilt departs the most from the other four. Again these differences can very well imply real differences between stations, such as local differences in air pollution that influence visibility (and thus optical thickness).

For the remainder of the research we decided to use the mean of all five stations for the 1966-2015 period. We studied the sensitivity of the results to leaving out stations and found that even though some details were different, it did not significantly alter any of the findings and conclusions.

\subsection{Okta and cloud amount}

Even though cloud amount is commonly indicated with the parameter okta, its translation to actual cloud amount as a fraction is necessary for usage in this paper. According to World Meteorological Organization guidelines (WMO, 2008) actual cloud amount should be indicated as 1 okta in case a single cloud is present in an otherwise completely clear-sky. Similarly, if a single hole exists in an otherwise overcast sky, cloud amount should be indicated as seven out of eight. Therefore, a cloud amount of 1 okta corresponds to 
Table 1. Details of the stations and the introduction data of the radiometers.

\begin{tabular}{lrrrrl}
\hline Station & WMO nr. & Lat $(\mathrm{N})$ & Long (E) & ALT $(\mathrm{m})$ & Introduction date \\
\hline De Kooy & 06235 & 52.924 & 4.785 & 0.5 & 24 September 1964 \\
De Bilt & 06260 & 52.101 & 5.177 & 2.0 & 10 May 1957 \\
Eelde & 06280 & 53.125 & 6.586 & 3.5 & 2 October 1964 \\
Vlissingen & 06310 & 51.442 & 3.596 & 8.0 & 10 April 1962 \\
Maastricht & 06380 & 50.910 & 5.768 & 114.0 & 5 March 1963 \\
\hline
\end{tabular}

a lower cloud amount than expected based on the numerical value of one-eighth. Similarly, a cloud amount of seveneighth corresponds to a larger value than indicated by its numerical value. Boers et al. (2010) evaluated observed cloud amounts expressed in oktas with fractional cloud amounts derived from all-sky observation of clouds using a total sky imager (an instrument sensitive to radiation in the visible part of the solar spectrum) and using a Nubiscope (an allsky scanning infrared radiometer). We adhere to the results of their study (their Sect. 2.3, Table 1) where for okta $0-8$ the following cloud fractions are given: $0.00,0.0615,0.2494$, $0.3751,0.5003,0.6256,0.7518,0.9507,1.00$.

In the analysis presented in the next section a practical problem occurred in distinguishing between radiation emanating from a completely clear-sky or from a sky with a single cloud but otherwise clear. In the latter case, provided that the cloud does not completely block the direct solar beam, it will be impossible to discern whether the radiative flux would have come from a sky with 0 okta. For this reason it was decided to take data from $c=0$ and $c=1$ together and designate the combined data as "clear-sky". A similar argument can be made for the radiation at the high end of cloudiness. Hence, data from $c=7$ and $c=8$ were lumped together as designating an "overcast" sky.

In this paper we use both the term cloud fraction and okta. When selecting radiation values for a particular okta value (index $j$ in Sect. 2), the cloud fraction attributable to that particular okta value (i.e. $c_{j}$ in Eq. 2 ) is used to compute the (proxy) radiation. The computation of the yearly mean fractional cloudiness (with index $k$ ), $c_{k}$ as per Eq. (A4), simply takes the average over all $c_{j}$ values occurring over the entire range of okta values.

\subsection{Discontinuity in 2002}

In 2002 the Human Observer was replaced by the Present Weather Sensor for visibility observations and by the ceilometer for cloud observations. While the former transition posed few problems in the analysis of data, such was not the case for the latter. When observing clouds the $\mathrm{Hu}-$ man Observer takes into account the full $360^{\circ}$ view of the horizon. A ceilometer only observes a narrow portion of the sky in vertical direction. Although the half-hour averaging of the cloud observations to some extent compensates for the absence of instantaneous hemispheric information, the two types of observation represent different methods of estimating cloud cover so that the conditional sampling of the radiation is significantly affected. For example, the digital nature of the ceilometer observation results in many more observations in the $c=0$ (cloudless) and the $c=8$ (overcast) cloud cover selection bin than obtained from the Human Observer (Boers et al., 2010). As a result, the selectively sampled radiation data in both okta bins will be contaminated by data recorded under fractionally cloudy conditions. Contamination by other okta values is also present for data selected for each of the 1-7 okta range but less than for overcast sky conditions. As a result, the selectively sampled radiation data showed distinct discontinuities in 2002.

To account for the discontinuity we decided to apply a so-called quantile-quantile correction to the frequency distribution of cloud coverage from the period after 2002 (during which the ceilometer was operative) and adjust it to the frequency distribution from the period before 2002 (during which the Human Observer was operative). The quantilequantile correction ( $\mathrm{Li}$ et al., 2010) is commonly used to adjust distributions of meteorological parameters of numerical models to observed distributions of the same parameters. As a first step cloud cover data (converted from okta to fractional cloudiness, see Sect. 3.4) from the period 2002-2015 were smoothed by a Gaussian filter with a half-width of two data points (i.e. $2 \mathrm{~h}$ ). This produced a smooth distribution which, when converted back to okta, yielded a distribution similar to, but not the same as, the okta distribution of the Human Observer. The next step was to do a quantile-quantile correction on the smoothed data. The credibility of a quantilequantile correction depends on whether it can be assured that the average distribution function as observed by the Human Observer does not change over the break (in case the Human Observer would have made the observations after the break). Although there were some long-term changes in the distribution function before the year 2002 they were small enough to assume the invariance of the distribution function over the break. With the application of the quantile-quantile correction the okta values and hence the fractional cloudiness values after the break assume new and/or corrected values that are applied as new and/or corrected discriminators in the selection of the radiative flux. 


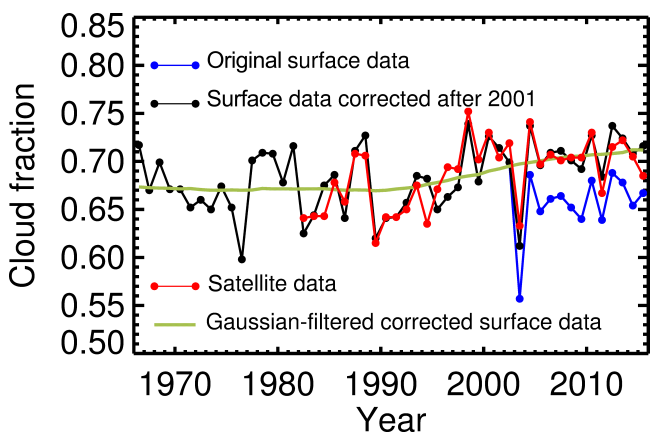

Figure 1. Surface-based cloud fraction estimates versus satellitebased estimates.

As a proof of soundness of the procedure we applied the quantile-quantile correction and recomputed the fractional cloudiness as the summation $\sum_{1}^{8} f_{j} c_{j}=c_{k}$ (see discussion beneath Eq. A4 in the Appendix) and compared the result to satellite observations derived from successive NOAA satellites (Karlsson et al., 2017). Figure 1 shows the results.

The NOAA data (red line) comprise an average over the Netherlands and have been bias corrected. It is clear that the surface data (black line) which are break-corrected after the year 2002 provide an excellent agreement to the NOAA data when compared to the data which are not breakcorrected (blue line). Note also that the data that are not break-corrected show a downward trend in cloudiness while the break-corrected data show an upward trend. These results are thus at odds with observations in Germany, close to the Netherlands (Ruckstuhl et al., 2010), where cloud cover seems to be declining at least until 2010.

\section{Results}

\subsection{Decomposing the all-sky radiative fluxes}

As a first step in understanding the relative impact of clear and cloudy skies on the all-sky radiative flux it is instructive to examine the manner in which the top-of-atmosphere (TOA) radiative flux is reduced by the various constituents and scattering and absorption mechanisms in the atmosphere (Fig. 2). The combined effect of all these processes is responsible for reducing the TOA radiative fluxes down to the observed all-sky radiative flux as indicated by the white line at the bottom of the figure. Figure 2 is a combination of calculations and observations. Observed are the all-sky flux (the white line at the bottom of the figure) and the clearsky flux (the white line in the middle). Starting from the top and moving downward, the first reduction of the TOA flux is due to Rayleigh scattering, namely downwards from 274 to $253 \mathrm{~W} \mathrm{~m}^{-2}$. Continuing downwards ozone absorption is responsible for a further reduction from 253 to $246 \mathrm{~W} \mathrm{~m}^{-2}$.

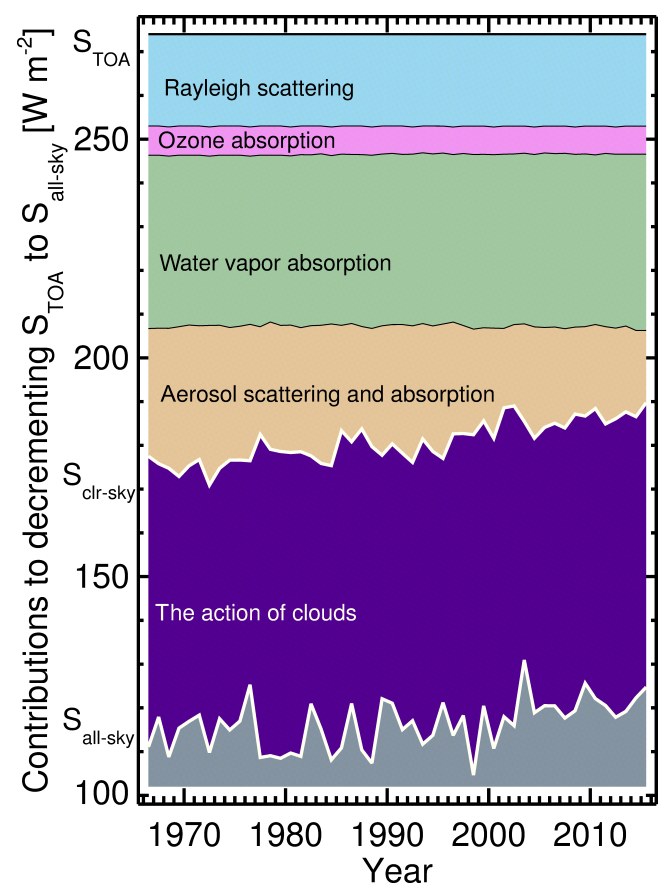

Figure 2. Impact on all-sky flux due to Rayleigh scattering, ozone absorption, water vapour absorption, aerosol scattering and absorption and the action of clouds.

Next, water vapour absorption reduces the radiative flux by a further $39 \mathrm{~W} \mathrm{~m}^{-2}$ from 246 to $207 \mathrm{~W} \mathrm{~m}^{-2}$. These three decrements were calculated from inputs from ERA-Interim (for the ozone and water vapour absorption) or surface pressure observations (for the Rayleigh scattering).

The next reduction is due to the aerosol scattering and absorption, which takes the radiative flux further down to the observed clear-sky flux (or more precisely the proxy) from 207 to $\sim 170 \mathrm{~W} \mathrm{~m}^{-2}$ around 1970 or to $\sim 185 \mathrm{~W} \mathrm{~m}^{-2}$ near 2015 with a steady increasing value during the intermediate years. The solid white line in the middle of the plot represents the clear-sky proxy flux. The rest of the reduction from the clear-sky radiative flux to the all-sky flux is entirely due to the action of clouds. The observed clear-sky proxy shortwave radiation shows that about $13.6 \mathrm{~W} \mathrm{~m}^{-2}$ has been added to the clear-sky radiation over a period of 5 decades. A trend value at $2.78 \pm 0.50 \mathrm{~W} \mathrm{~m}^{-2}$ decade $^{-1}$ was calculated. The upward trend in clear-sky radiation is thus deemed to be strongly significant. The lower white solid line represents the all-sky radiation which is derived straight from the publicly available climate data sources. It shows considerable short-term variations but overall there is a positive trend. The trend value was calculated as $1.81 \pm 1.07 \mathrm{~W} \mathrm{~m}^{-2} \mathrm{decade}^{-1}$ and is thus also considered significant.

When comparing the different contributions there are three important points to be considered. First, the combined effects of Rayleigh scattering, ozone and water vapour absorption are constant over time. Even though there is a slight increase 


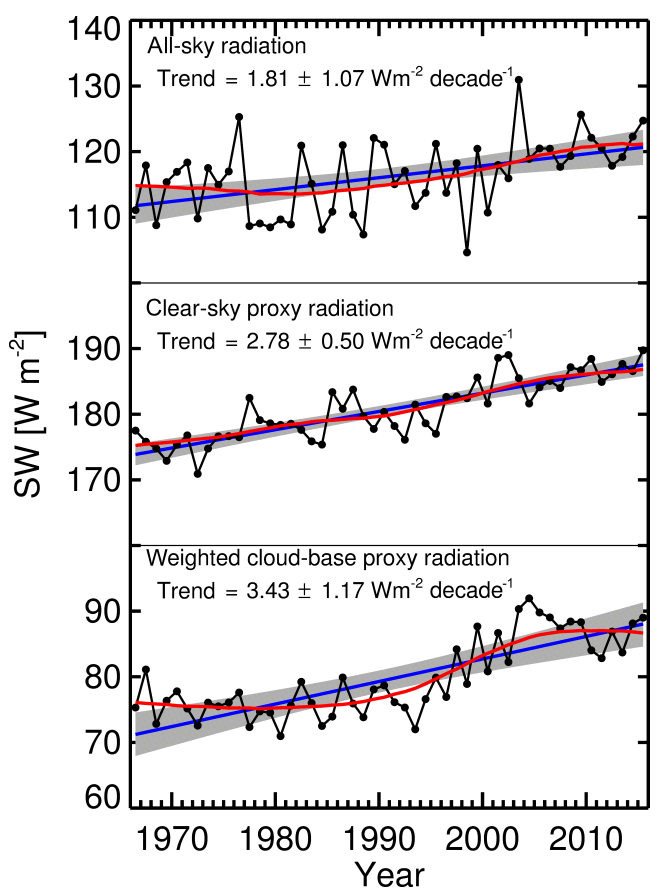

Figure 3. All-sky, clear-sky proxy and cloud-base proxy radiation as a function of time. Blue lines are the regression fits with the grey area as the uncertainty around the fit. The red lines are 21-point Gaussian filter smoothers.

in water vapour path over the 50-year period, this is not reflected in any discernable decrease in radiative flux. Second, despite the absence of any significant trends in the respective radiative reductions they make up a very substantial part of the overall reduction from the TOA radiative flux to the allsky flux (40-50\%). Third, the two-pronged action of clouds of (1) blocking part of clear-sky flux in reaching the surface and (2) scattering radiation inside the clouds is considerably larger than the action of scattering and absorption of radiation by aerosols in reducing the TOA radiative flux. The former ranged from double the latter at the beginning of the period to triple the latter at the end of the period.

Figure 3 shows the measured all-sky radiation and the proxy clear-sky and weighted cloud-base radiation. Linear regression lines (blue) as well as a 21-point Gaussian fit (red) are shown in the figure. There is a weak minimum in all-sky radiation in 1984 which is matched by a minimum in cloudbase radiation around 1982-1984. In contrast the clear-sky radiation has an upward trend throughout the entire period. All trends are significant when taken over the entire period.

Figure 4 shows the all-sky radiation and its proxy. The difference between the two averaged over the 50 years is $4.34 \%$. However, there is some year-to-year variability. For example in the years just prior to 2000 the differences are less than 1\%, while in the period 2012-2015 it is about $8 \%$. Such variations are the result of (a) natural year-to-year variations in the distributions of zenith angles attributable to the

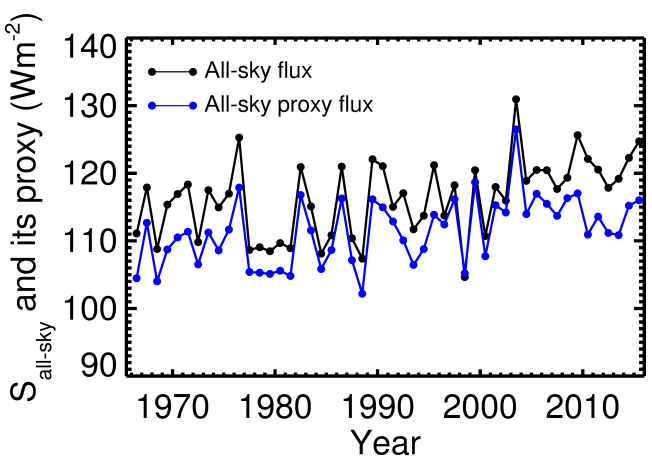

Figure 4. The all-sky radiation and its proxy.

individual okta values for the all-sky radiation, (b) possibly more systematic changes to the distribution of sun angles per okta value (i.e. seasonal changes on a multi-year timescale) and (c) the uncertainties in the line fits necessary to compute the proxy radiation. At any rate there appears to be a systematic bias between the two time series of $4 \mathrm{~W} \mathrm{~m}^{-2}$. This is primarily caused by the fact that in the Netherlands mostly cloudless skies occur in summer months when the sun is high in the sky. This means that when the proxy radiation is computed using the marginal distribution of sun angles (see Appendix) there will be an inevitable shift towards lower sun angles (i.e. smaller radiation values) in comparison to the real flux for which the conditional distribution of sun angles is used in its computation. This situation is peculiar to the Netherlands and is unlikely to be a universally observable feature. Because of these differences there will also be some differences between the trend values of the real (observable) and proxy (calculated) fluxes to be calculated later on (see later in Table 2).

Figure 5 shows the key result of this paper namely the reconstruction of the trend in the all-sky (proxy) flux out of its three main components as formulated in Eq. (3). Here the last term, a cross-correlation term, is not shown on account of its very small yearly values (less than $0.5 \mathrm{~W} \mathrm{~m}^{-2}$ ). The black curve shows the variation in all-sky proxy radiation as a function of time. Note again that this function is slightly different from the real all-sky radiation data as its construction is based on the proxy data. Even so, the fluctuations and trends in the proxy data are clearly very close to the fluctuations and trends as observed in the real all-sky data in Figs. 3 and 4. However, the Gaussian-filtered data indicate that the weak minimum in the original data is replaced by a (close to) constant value in the proxy data. The red curve is the contribution to the trend in all-sky proxy radiation due to the trend in cloud amount. Cloud amount is increasing and as a consequence the contribution to the overall trend in solar radiation is negative. The green line is the contribution to the trend in all-sky proxy radiation as a result of the positive trend in clear-sky proxy radiation, but modulated by the average fraction of time that it is actually clear $(32 \%)$. The 
Table 2. Summary of trend analysis. Except for the fractional cloudiness, all parameters have $\mathrm{W} \mathrm{m}^{-2} \mathrm{decade}^{-1}$ as a unit. Fractional cloudiness has no unit and the indicated trend is computed per decade. Whether or not the indicated trend is significant is indicated by the star in the column "uncertainty".

\begin{tabular}{lrrr}
\hline Type & Period & Trend & Uncertainty \\
\hline Fractional cloudiness & $1966-2015$ & 0.0097 & $0.0062^{*}$ \\
& $1966-1984$ & -0.0055 & 0.0344 \\
All-sky radiation & $1984-2015$ & 0.0205 & $0.0117^{*}$ \\
& $1966-2015$ & 1.81 & $1.07^{*}$ \\
All-sky proxy radiation & $1966-1984$ & -1.40 & 4.19 \\
& $1984-2015$ & 3.30 & $1.55^{*}$ \\
Clear-sky proxy radiation & $1966-2015$ & 1.89 & $0.78^{*}$ \\
& $1966-1984$ & 0.39 & 3.86 \\
Cloud-base proxy radiation & $1984-2015$ & 2.30 & $1.68^{*}$ \\
& $1966-2015$ & 2.78 & $0.50^{*}$ \\
& $1966-1984$ & 1.22 & 2.14 \\
Fractional cloudiness term of Eq. (3) & $1984-2015$ & 3.46 & $1.35^{*}$ \\
& $1966-2015$ & 3.43 & $1.17^{*}$ \\
& $1966-1984$ & -0.77 & 2.01 \\
Clear-sky proxy term of Eq. (3) & $1984-2015$ & 4.94 & $2.30^{*}$ \\
& $1966-1984$ & -1.06 & $0.67^{*}$ \\
& $1984-2015$ & -2.22 & 3.30 \\
Cloud-base proxy term of Eq. (3) & $1966-2015$ & 0.88 & $1.19^{*}$ \\
& $1966-1984$ & 0.39 & $0.16^{*}$ \\
& $1984-2015$ & 1.09 & 0.68 \\
& $1966-2015$ & 2.35 & $0.83^{*}$ \\
& $1966-1984$ & -0.53 & 1.38 \\
& $1984-2015$ & 3.37 & $1.57^{*}$ \\
\hline
\end{tabular}

blue line is the contribution to the trend in all-sky radiation as a result of the positive trend in proxy cloud-base radiation. It has a broad minimum, but modulated by the fraction that it is cloudy on average (68\%). Each curve represents a perturbation with respect to its average and the large tick marks represent intervals of $10 \mathrm{~W} \mathrm{~m}^{-2}$.

A number of intermediate conclusions can be drawn at this point:

1. The cloud base and cloud cover contributing trends are of the same order of magnitude whereas the clear-sky trend contribution is less significant than either one of them.

2. As the mean fractional cloudiness at 0.68 is larger than 0.50 , the contribution to the all-sky flux due to a trend in cloud-base radiation has a comparatively larger weight than the contribution of the trend in clear-sky radiation.

3. The increase in cloud cover results in a negative trend contribution to the trend in all-sky (proxy) radiation, which thus dampens the strong trend contribution due to the increasing cloud-base proxy radiation. The implication is that clouds have become (optically) thinner but at the same time more frequent, the cause of which is unclear.
4. The short-term variations in all-sky radiation are almost entirely due to the short-term variations in fractional cloudiness.

5. The weak minimum (constant) in all-sky (proxy) radiation is linked to trends in clouds, but not to the trend in clear-sky radiation.

Table 2 summarizes the results of the trend analysis. Here, a subselection is also made according to the time period over which trend analysis is performed. Significance is indicated in the last column. Note that both the trends in all-sky radiation and the trend in all-sky proxy radiation are given in the table. The trend in all-sky radiation is simply inferred from the data whereas the trend in all-sky proxy radiation is computed from Eq. (3). Thus, contrary to common notion the trend in measured all-sky radiation cannot be recovered from the trends in proxy data. It is only the all-sky proxy trend that can be recovered from the clear-sky and cloud-base proxy terms and the fractional cloudiness term of Eq. (3). Note that the fractional cloudiness term in Eq. (3) is a scaled version of the trend in fractional cloudiness, whereas the other two are scaled versions of the trend in clear-sky proxy radiation and cloud-base proxy radiation.

Inspection of the table indicates that none of the trends (including those of the clear-sky proxy radiation) are signifi- 


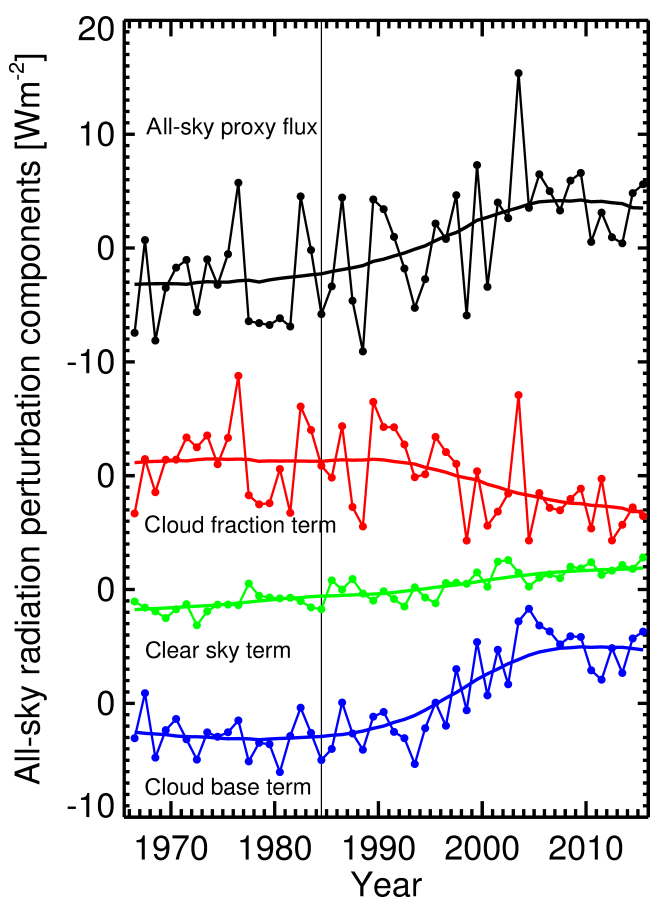

Figure 5. All-sky radiation perturbation components. Terms are indicated in the graph; 21-point Gaussian filter smoothers are drawn through the curves.

cant in the period 1966-1984. All significant trends occur in the period 1984-2015. In comparing the trends between allsky and all-sky proxy flux we find that for the period 19662015 both trends are almost the same. For the period 19661984 they are different in sign (but neither trend is deemed significant). For the period 1984-2015 both are significantly positive but the trends differ by $30 \%$ from each other. As explained above (see under Fig. 4) such differences are to be expected due to the fact that the method to calculate the proxy all-sky flux uses the marginal distribution while the calculation of the all-sky radiation uses the conditional distributions of sun angles, which can exhibit year-to-year variations or multi-year seasonal changes.

Two-thirds of the strong upward trend in cloud-base proxy radiation is offset by the cloud fraction trend term in the same period. To our knowledge these calculations are the first of their kind and demonstrate the relative importance of the impacts of clear and cloudy skies on the all-sky radiation. Trend values for the all-sky radiation all fall within the bounds of Sanchez-Lorenzo et al. (2015) given by their comprehensive summary of Europe's observations. For the clear-sky proxy radiation the trend is positive throughout the entire period and the absence of a curvature matching that of the all-sky radiation does not suggest a very strong causal link with it. In contrast the curvature of the cloud-base proxy radiation curve much more resembles that of the all-sky radiation. Because the fractional cloud cover term partly compensates the strong upward trend of the cloud-base curve after 1985, it

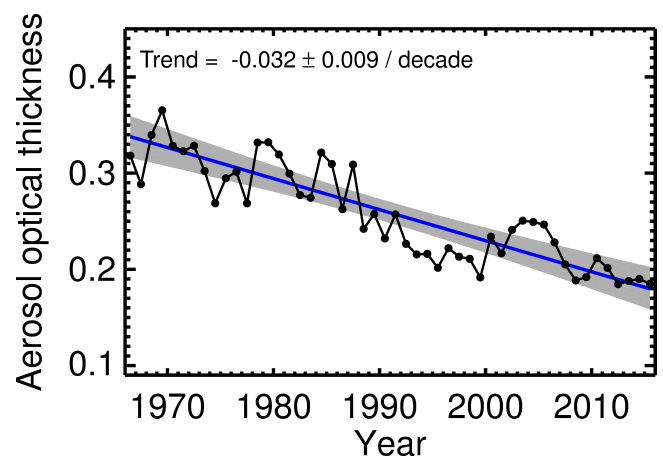

Figure 6. Aerosol optical thickness derived from visibility observations.

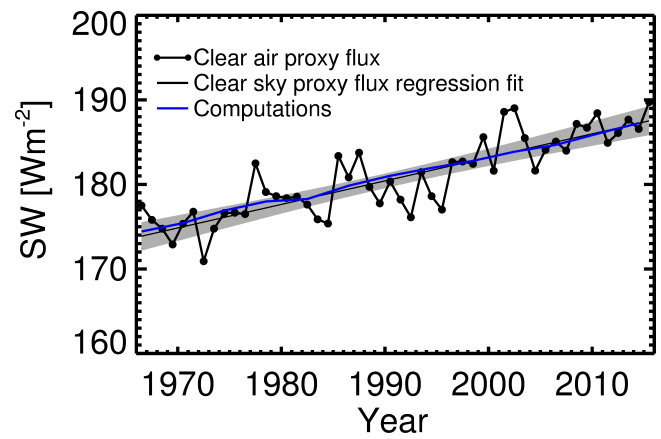

Figure 7. Clear-sky radiation observations matched by radiative transfer computations.

strongly suggests that for the Netherlands cloud processes are the dominant factor that impact the shape of the all-sky radiation time series.

\subsection{Aerosol-radiation interaction}

To investigate the possibility of aerosol-radiation interaction the median aerosol optical thickness is derived from the visibility observations. Next radiative transfer model calculations were performed to compute the solar radiation. Figure 6 shows the time series of median aerosol optical thickness for the Netherlands. Until about 1985 the optical thickness has a weakly downward trend albeit with considerable year-toyear variations. After 1985 there is a distinct downward trend that remains present until the end of the time series in 2015. Overall trend is -0.032 per decade and is significant.

Figure 7 shows the results from radiative transfer computation compared to the clear-sky flux. The solid black and accompanying shading represents the best fit through the data (the points connected by a black line). The blue line is the result of calculating the clear-sky radiation using the aerosol optical thickness in Fig. 6 as an input, with a fixed value of the single scattering albedo of 0.90 . The calculations indicate a remarkable agreement with the observed clear-sky ra- 


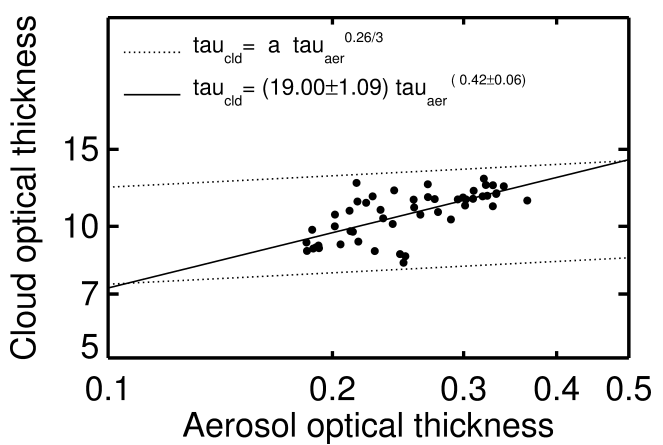

Figure 8. Cloud optical thickness as a function of aerosol optical thickness. The broken lines are the suggested dependencies of the two optical thicknesses assuming that ACI-I is valid. The solid line is the actual fit through the data.

diation. The blue line falls entirely within the shaded area of uncertainty of the slope through the data.

The accuracy of the modelled radiation curves is dependent upon the accuracy of the optical thickness derived from the visibility observations and the value of the single scattering albedo. If the scaling depth used to match the optical thickness observations to satellite and surface-based radiation data (Boers et al., 2015) is changed, so will the position of the model output (blue line) change with respect to the clear-air data $\left(\delta \mathrm{SW}=5-6 \mathrm{~W} \mathrm{~m}^{-2}\right.$ for $\left.\delta \tau=-0.1\right)$.

There is, however, no useful information on the time dependence of the single scattering albedo; its mean value is also not clear. The value of 0.90 as used here reflects a compromise between the necessity of having to assign it a value less than 1 due to the presence of radiation absorbing aerosols (black carbon and organic aerosols) and the prevalence of pure scattering aerosols in an environment of high relative humidity (sulfates and nitrates), which tend to keep the single scattering albedo at a high value.

However, the overall conclusion is that the reduction in aerosol concentration resulting in a reduction in aerosol optical thickness is a very strong candidate for explaining the overall increase in clear-sky solar radiation. This implies that there is a compelling argument that ARI i.e. the direct aerosol effect, is responsible for the decadal change in clear-sky radiation.

\subsection{Aerosol-cloud interaction}

Concerning ACI-I we plotted the left and right sides of the function described in Eq. (9). Here (Fig. 8) the cloud optical thickness for clouds has been derived from the monotonic relationship between solar radiation and cloud optical thickness and using the mean weighted cloud-base radiation (bottom curve in Fig. 3) as the radiative input. The cloud optical thickness that is thus derived constitutes the left side of Eq. (9). The right side of Eq. (9) is based on the aerosol optical thickness data as shown in Fig. 6. According to Fig. 8, there is indeed an indication that there may be a link between the two optical thicknesses but the regression line has a larger slope than suggested by Eq. (9). This suggests that there may be other mechanisms that play a role in changing the cloud optical thickness. The most likely candidate responsible for these additional changes is a decadal thinning of clouds. However, there is no confirmation by independent data sources suggesting that such thinning has indeed taken place over the course of 5 decades.

Under ACI-II cloud amount is governed by precipitation. Here a reduction in aerosols over time would increase the size of cloud droplets, thus enhancing the fallout of liquid water and thus reducing cloud amount. However, data shown in Fig. 1 indicate that cloud fraction is increasing after 1985 when at the same time the aerosol optical thickness decreases. This does not necessarily mean that ACI-II is not operative but that other factors (such as large-scale synoptic changes) at least overwhelm any possible cloud cover changes due to ACI-II.

\section{Discussion and conclusions}

Our derivation of a trend equation for the all-sky radiation shows that there are five parameters that influence the trend, namely (1) a trend in fractional cloudiness, (2) a trend in clear-sky radiation, (3) a trend in cloud-base radiation, (4) the mean over 5 decades of the fractional cloudiness and (5) the difference between the means over 5 decades of the cloudbase and the clear-sky radiation. It is therefore not surprising that it has been difficult up to now to come up with any firm conclusions about the relative importance of trends in clouds or clear-sky radiation in contributing to the trend in all-sky radiation. This situation is further hampered by difficulties in the derivation of clear-sky and cloud-base radiation, requiring a specialized analysis removing the year-to-year internal fluctuations in radiation estimates. They are the results of periodic synoptic conditions that favour certain cloudiness conditions. An analysis of annual means of radiation selected under specific okta values will produce unrealistic results, as noted by Ruckstuhl et al. (2010). In order to overcome this last issue we have cast the problem of estimating annual mean radiation in a two-dimensional framework with cloud fraction (okta) and cosine of solar zenith angle as the two controlling variables. A proxy radiation is derived by fitting per okta value a function that is solely dependent upon cosine of zenith angle. Next annual means are computed using the annually constant distribution of cosine values. Stable values of radiation ensue from which trends can be calculated.

Our analysis comprises 50 years of hourly radiation, cloudiness and visibility data at the five principal climate stations in the Netherlands. We summarize the main conclusions of this work.

1. The three most important mechanisms reducing the TOA radiation to the observed all-sky radiation are ab- 
sorption of radiation by water vapour and scattering and absorption by aerosols and clouds. Over the Netherlands the reduction in radiation due to water vapour absorption is actually larger than from aerosol scattering and absorption. However, as there is no trend in water vapour, there is no trend in the all-sky radiation due to trends in water vapour.

2. Trends in clear-sky and cloud-base radiation and fractional cloudiness are all important in contributing to the trend in all-sky radiation.

3. Over the Netherlands the clear-sky trend is weighted by 0.32 , which is 1 minus the mean of fractional cloud cover over 5 decades, and the cloudy-sky trend is weighted by 0.68 (i.e. the the mean of fractional cloudiness over 5 decades). Therefore, in the Netherlands a trend in cloud-base radiation has double the weight of a clear-sky radiation trend in contributing to the all-sky radiation trend. Thus, in a general sense this means that the actual value of fractional cloudiness, which has a strong regional dependence, exerts a considerable control over the relative importance of clear-sky and cloudbase radiation trends.

4. Over the Netherlands the trend in fractional cloudiness is significantly positive in the period after 1985 and because this trend is multiplied by the (negative) difference between the decadal means of cloud-base and clear-sky radiation, it contributes as a negative trend to the trend in all-sky radiation. As the literature suggests (e.g. Norris, 2005) there are significant regional differences in long-term trends in cloud cover, which indicates that strong regional differences will exist in its contribution to the trend in all-sky radiation.

5. As found in most studies (see summary of SanchezLorenzo et al., 2015), a minimum in all-sky radiation is found around 1985 . The negative trend of $-1.4 \mathrm{~W} \mathrm{~m}^{-2}$ up to 1985 is weaker than the average of Europe $\left(-2.5 \mathrm{~W} \mathrm{~m}^{-2}\right)$. The upward trend from 1985 onwards of $2.3 \mathrm{~W} \mathrm{~m}^{-2}$ is also weaker than the average of Europe $\left(3.2 \mathrm{~W} \mathrm{~m}^{-2}\right)$.

6. The minimum in all-sky radiation is not matched by a corresponding minimum in clear-sky proxy radiation. A trend of $1.22 \mathrm{~W} \mathrm{~m}^{-2}$ is found over the earlier period which increased to $3.40 \mathrm{~W} \mathrm{~m}^{-2}$ later on. After significant amounts of local natural gas were found in the late 1950s the Netherlands became a very early (1960-1965) adopter of cleaner fuels, which may explain the increase in clear-sky radiation in the earlier period (1966-1985).

7. The trend in cloud-base radiation has a similar shape as that of the all-sky radiation. It is weakly negative before $1985\left(-0.77 \mathrm{~W} \mathrm{~m}^{-2}\right)$ and strongly positive there- after (4.94 $\mathrm{W} \mathrm{m}^{-2}$ ). Consequently, the conclusion is justified that the curvature/weak minimum in all-sky radiation around 1985 is caused mostly by the cloud-base radiation.

8. As our techniques are able to isolate the clear-sky radiative component it has been possible to study the attribution of changes in aerosol content to the observed trend in clear-sky radiation. Radiative transfer calculations demonstrate that the increase in clear-sky radiation can be completely explained by a concomitant decrease in aerosol optical thickness. This strongly suggests that the ARI (the direct aerosol effect) is a prime candidate to explain the observed increase in clear-sky radiation.

9. Similarly, ACI-I and ACI-II have been studied to understand their potential impact on the all-sky radiation. Neither is shown to have a dominant contribution to the trend in the overall all-sky flux but the potential influence of ACI-I and ACI-II cannot be ruled out by the data; there may be other influencing mechanisms that mask the impact of ACI-I and ACI-II such as decadal changes in cloud thickness and fractional cloudiness as a result of large-scale synoptic phenomena.

A prerequisite required for our method to work is the availability of simultaneous time series of radiation, cloudiness and visibility. The first two are necessary to resolve the difference between clear and cloudy-sky signals in the radiation data, a method which in this paper has been called the determination of "proxies". Additional observations of visibility are necessary to understand the possible influence of aerosols on radiation.

There are a number of ways to improve and/or facilitate this work in the future:

1. The practice of observing different parameters simultaneously can be improved by a more optimal consideration of the impact of one parameter on another. For example, aerosols and clouds impact radiation, but radiation is recorded as an hourly average, while clouds and visibility parameters are recorded as averages of smaller time intervals. Often these different recording and averaging intervals are based on WMO standards. Yet, they inhibit the analysis and interpretation of their physical links. It would be better if averaging times were standardized more uniformly or if the basic data underlying the averages became available.

2. The relative contribution to the all-sky radiation of cloud thickness remains unclear. Therefore, the potential impact of ACI-I and ACI-II cannot be unambiguously quantified. The best way to resolve this issue is by adding observations of clouds using a cloud radar and a cloud lidar. As clouds are largely transparent to radar probing, cloud thickness and its long-term variations can thus be derived. Here, supersites such as those of 
the Atmospheric Radiation Measurement program and CloudNet or long-term data from CloudSat could be of great assistance. Passive radiation data from satellites are less suitable as they only record radiation emanating from the top of clouds or from the layer just beneath cloud top.

3. The impact of changes in the aerosol single scattering albedo on the radiative transfer calculations is unclear. This situation is best resolved by direct observations of the single scattering albedo including its wavelength dependence. However, this suggestion only works for future studies as observations of aerosol single scattering albedo have hardly been performed in the past. It may be that regional modelling of past aerosol composition and physical and optical properties may alleviate the historical lack of single scattering albedo data.
Data availability. The data used in this paper can be downloaded from the KNMI website: http://www.knmi.nl/nederland-nu/ klimatologie/uurgegevens. 


\section{Appendix A}

\section{A1 Averaging using real data}

Here we provide a full derivation of the analysis leading to Eqs. (1) and (3) in the main text. The essential elements in this analysis are (1) a transition from "real" data to "proxy" data, which constitutes a different way of averaging yearly data; (2) expressing the all-sky proxy radiation as a linear combination of clear-sky and cloud-base proxy radiation; and (3) a perturbation analysis from which trends can be calculated.

We analyse the trends of time series of global radiation $S_{k}$, where $S$ is the yearly-averaged global radiation and $k$ is the index of a year in the period 1966-2015. We write $S_{k}$ as a function of two controlling variables: fractional cloudiness $c$ and cosine of solar zenith angle $\mu_{0}=\cos \left(\theta_{0}\right)$. Each of these two parameters varies between 0 and 1 (i.e. when the sun is below the horizon the variable $\mu_{0}$ is set to zero).

In the observations from meteorological stations the global radiation comes in discrete values, in our case as hourly averages, 8760 or 8784 values in a year. Each of these hourly averages is thus assigned a specific value of $\mu_{0}$, namely the mid-point of the hour. The index $i$ is the bin index of counting over $\mu_{0}$. Whether to build up the probability space for the $\mu_{0}$ bins of $\mu_{0}$ can be selected at the analyst's discretion (for example with width 0.05 ).

Observations of cloudiness are usually assigned in oktas. Okta values (0-8) are associated with specific margins of fractional cloud coverage (see table 1 of Boers et al., 2010). We will designate the fractional cloudiness associated with each okta value as $c_{j}$, where $j=0-8$. The yearly bivariate distribution function can then be constructed as

$p_{k}\left(\mu_{0 i}, c_{j}\right)=\frac{N_{i j k}}{N_{k}}$,

where $N_{i j k}$ is the number of observations in a single bin and

$$
\sum_{i} \sum_{j} N_{i j k}=N_{k}
$$

and

$\sum_{i} \sum_{j} p_{k}\left(\mu_{0 i}, c_{j}\right)=1$

The convention used in this paper is that when no superscript is used over the summation sign, the summation is over the entire range of subscript values. Marginal distribution functions of Eq. (A1a) are

$f_{k}\left(c_{j}\right)=\sum_{i} p_{k}\left(\mu_{0 i}, c_{j}\right)=\frac{\sum_{i} N_{i j k}}{N_{k}}=\frac{N_{j k}}{N_{k}}$, where $f_{k}\left(c_{j}\right)$ is the fractional occurrence of cloud cover within a specific okta value, and

$f\left(\mu_{0 i}\right)=\sum_{j} p_{k}\left(\mu_{0 i}, c_{j}\right)=\frac{\sum_{j} N_{i j k}}{N_{k}}=\frac{N_{i k}}{N_{k}}$,

where $f\left(\mu_{0 i}\right)$ is the distribution of cosines of solar zenith angle. While the distribution $f\left(\mu_{0 i}\right)$ is invariant with time as it is solely dependent on the latitude of the observations, $f_{k}\left(c_{j}\right)$ is varying with time due to yearly and possible decadal trends. Yearly-averaged fractional cloudiness $c_{k}$ is found as the expected value of $c$ of the marginal distribution $p_{k}$ :

$c_{k}=\sum_{j=1}^{8} c_{j} f_{k}\left(c_{j}\right)$.

The yearly-averaged $S_{k}$ can be computed as the expected value of $S$, namely the double summation over all values of $c$ and $\mu_{0}$ that jointly occur in a single year:

$S_{k}=\sum_{i} \sum_{j} S_{k}\left(\mu_{0 i}, c_{j}\right) p_{k}\left(\mu_{0 i}, c_{j}\right)$.

Here $S_{k}\left(\mu_{0 i}, c_{j}\right)$ is the average value of $S_{k}$ in the bin $(i, j, k)$.

For each okta class we can derive the distribution of zenith angles as the conditionally sampled bivariate distribution at the specific okta class $c_{j}$ :

$f_{k}\left(\mu_{0 i} \mid c_{j}\right)=\frac{p_{k}\left(\mu_{0 i}, c_{j}\right)}{f_{k}\left(c_{j}\right)}$.

We now obtain the yearly-averaged global radiation in each okta class as the expected value of the hourly global radiation data sampled conditionally with okta class:

$S_{c_{j}, k}=\sum_{i} S_{k}\left(\mu_{0 i}, c_{j}\right) f_{k}\left(\mu_{0 i} \mid c_{j}\right)$.

Combining Eqs. (A5), (A6) and (A7) yields

$S_{k}=\sum_{j} f_{k}\left(c_{j}\right) S_{c_{j, k}}$.

Provided that there are adequate observations of cloudiness to select each observation of global radiation according to the okta class in which it occurs, it is possible to calculate $S_{c_{j}, k}$ and hence $S_{k}$ directly from the observations.

The assumption we make at this point is that the hourly observation of radiation is a linear combination of a clear-sky term and a cloud-base term, each weighted by their occurrence:

$S_{k}\left(\mu_{0 i}, c_{j}\right)=S_{k}\left(\mu_{0 i}, c_{0}\right)\left(1-c_{j}\right)+S_{k, \mathrm{cb}}\left(\mu_{0 i}, c_{j}\right) c_{j}$,

where $S_{k, \mathrm{cb}}$ is the cloud-base radiation. Although Eq. (A9) is a customary approximation, it is almost certainly incomplete as it neglects possible contributions to the flux from 
three-dimensional photon scattering between clouds, in particular when cloud cover is broken. However, to our knowledge no useful correction to Eq. (A9) has been published taking such scattering into account. To produce a yearly average this function is multiplied by the conditional distribution $f$ (from Eq. A6) and summed over all observations occurring in the specific okta class:

$$
\begin{aligned}
& \sum_{i} S_{k}\left(\mu_{0 i}, c_{j}\right) f_{k}\left(\mu_{0 i} \mid c_{j}\right)= \\
& \quad \sum_{i} S_{k}\left(\mu_{0 i}, c_{0}\right) f_{k}\left(\mu_{0 i} \mid c_{j}\right)\left(1-c_{j}\right) \\
& \quad+\sum_{i} S_{k, \mathrm{cb}}\left(\mu_{0 i}, c_{j}\right) f_{k}\left(\mu_{0 i} \mid c_{j}\right) c_{j}
\end{aligned}
$$

We thus find that

$S_{c_{j} k}=S_{c_{0} k}\left(1-c_{j}\right)+S_{\mathrm{cb}, j, k} c_{j}+R_{1}$

with

$R_{1}=\sum_{i} S_{k}\left(\mu_{0 i}, c_{0}\right)\left[f_{k}\left(\mu_{0 i} \mid c_{j}\right)-f_{k}\left(\mu_{0 i} \mid c_{0}\right]\left(1-c_{j}\right)\right.$

and

$S_{\mathrm{cb}, j, k}=\sum_{i} S_{k, \mathrm{cb}}\left(\mu_{0 i}, c_{j}\right) f_{k}\left(\mu_{0 i} \mid c_{j}\right)$

In Eq. (A11c) all cloud-base radiation in a single okta class is simply lumped together. We now calculate the total radiation using Eq. (8).

With further manipulation we then find that

$$
\begin{aligned}
& S_{k}=S_{c_{0} k}\left[1-\sum_{j=1}^{8} f_{k}\left(c_{j}\right) c_{j}\right]+\sum_{j=1}^{8} f_{k}\left(c_{j}\right) c_{j} S_{c b, c_{j k}}+ \\
& \sum_{j} f_{k}\left(c_{j}\right) \sum_{i} S_{k}\left(\mu_{0 i}, c_{0}\right)\left[f_{k}\left(\mu_{0 i} \mid c_{j}\right)-f_{k}\left(\mu_{0 i} \mid c_{0}\right]\right. \\
& \left.\quad=S_{c_{0} k}\left[1-c_{k}\right)\right]+c_{k} S_{\mathrm{cloud}, k}+\sum_{j} \sum_{i} S_{k}\left(\mu_{0 i}, c_{0}\right) f_{k}\left(c_{j}\right) \\
& {\left[f_{k}\left(\mu_{0 i} \mid c_{j}\right)-f_{k}\left(\mu_{0 i} \mid c_{0}\right)\right]}
\end{aligned}
$$

from which it follows that

$$
\begin{gathered}
S_{k}=S_{c_{0} k}\left[1-c_{k}\right]+c_{k} S_{\text {cloud }, k}+R_{2} \\
R_{2}=\sum_{j} \sum_{i} S_{k}\left(\mu_{0 i}, c_{0}\right) f_{k}\left(c_{j}\right) \\
{\left[f_{k}\left(\mu_{0 i} \mid c_{j}\right)-f_{k}\left(\mu_{0 i} \mid c_{0}\right)\right] .}
\end{gathered}
$$

Here

$$
S_{\text {cloud }, k}=\frac{\sum_{j=1}^{8} f_{k}\left(c_{j}\right) c_{j} S_{\mathrm{cb}, c_{j} k}}{\sum_{j=1}^{8} f_{k}\left(c_{j}\right) c_{j}} .
$$

The rest terms $R_{1}$ and $R_{2}$ stem from the fact that the summation over values of the cosine of solar zenith angle is different for each okta class. Nevertheless it is expected that both terms are small as the summations in $R_{1}$ and $R_{2}$ are done over small terms that are positive as well as negative and thus will partly cancel. The parameter $S_{\text {cloud, } k}$ is the cloud-base radiation weighted by cloud fraction.

\section{A2 Averaging using proxy data}

It has long been recognized that $S_{c_{j} k}$ has large year-to-year fluctuations because $p_{k}\left(\mu_{0 i}, c_{j}\right)$ varies from year to year. Extended periods of cloudiness of certain types that influence $p_{k}\left(\mu_{0 i}, c_{j}\right)$ are associated with synoptic systems that may occur randomly during the year. This means that trend analysis based on Eq. (A13) will be subject to large uncertainties that can only be alleviated by collecting data over large areas so that different synoptic systems are sampled at the same time (Liepert, 2002) or by averaging $S_{c_{j} k}$ over several years and then performing trend analysis on the reduced and averaged data set (Liepert and Tegen, 2002). Over a relatively small region like the Netherlands, Eq. (A13) is unsuitable to use. In fact Ruckstuhl et al. (2010) demonstrated that the use of the radiation data in their pure form would lead to wrong interpretations of trends. To reduce the uncertainty in estimates of $S_{c_{j} k}$, in particular when estimating the global radiation under cloudless skies, $S_{c_{0} k}$, some investigators have resorted to fitting an "umbrella" function of clear-sky radiation over all observations within 1 year (Long et al., 2009; Ruckstuhl et al., 2010) based, for example, on discrimination of clear skies by analysis of direct and diffuse radiation. In our formulation the approach of fitting an umbrella function is equivalent to a procedure whereby $S_{k}\left(\mu_{0 i} \mid c_{0}\right)$ is fitted by a function $G_{c_{0 k}}\left(\mu_{0 i}\right)$. When we proceed in this way, the parameter $S_{\mathrm{p}, c_{0} k}$, which is a proxy for $S_{c_{0} k}$, is calculated as

$S_{\mathrm{p}, c_{0} k}=\sum_{i} G_{c_{0} k}\left(\mu_{0 i}\right) f\left(\mu_{0 i}\right)$.

There are strong theoretical arguments to suggest that $G_{c_{0} k}\left(\mu_{0 i}\right)$ is a monotonically increasing function of $\mu_{0 i k}$ given a specific value of $c_{j}$. The use of the marginal distribution $f\left(\mu_{0 i}\right)$ in the summation ensures that the entire distribution of cosines of solar zenith angles representative for the location at hand is used in the calculation rather than conditional distribution $f_{k}\left(\mu_{0 i} \mid c_{0}\right)$, which is highly variable from year to year and for which only a summation over a limited set of observations can be used.

In this paper the approach will be to generalize Eq. (A15) to all nine okta values as

$S_{\mathrm{p}, c_{j} k}=\sum_{i} G_{c_{j} k}\left(\mu_{0 i}\right) f\left(\mu_{0 i}\right)$.

In other words we will calculate functions of the type $G_{c_{j} k}\left(\mu_{0 i}\right)$ for each okta value using the observations at hand. 
The notion that the functions $G_{c_{j} k}\left(\mu_{0 i}\right)$ are monotonically increasing with $\mu_{01}$ comes from Beer's law, which states that for a single wavelength only the optical thickness of the atmosphere and $\mu_{0 i}$ itself are parameters controlling the change in downwelling radiation with $\mu_{0 i}$ :

$S_{\mathrm{s}}=\mu_{0} S_{\mathrm{e}} \exp \left(-\tau / \mu_{0}\right)$

Here $S_{\mathrm{s}}$ is the downwelling radiation at the surface, $S_{\mathrm{e}}$ is the extraterrestrial radiation and $\tau$ is the optical thickness of the atmosphere.

Even though the global radiation is a wavelengthintegrated quantity, the scattering through the atmosphere consisting of water droplets, ice crystals and aerosols at high relative humidity can in first order be assumed to be conservative. Therefore, it is reasonable to assume that $G_{c_{j} k}\left(\mu_{0 i}\right)$ has a functional form resembling Eq. (A17). When regressed through data taken over an entire year the fitted line has a parameter akin to the yearly-averaged optical thickness of the atmosphere as its sole controlling variable.

Consequently, we will adopt the function

$G\left(\mu_{0}\right)=\mu_{0} A \exp \left(-B / \mu_{0}\right)$,

where $B$ is a parameter depending on $\mu_{0}$ according to

$B\left(\mu_{0}\right)=\alpha \mu_{0}^{\beta}$.

The parameters $\alpha$ and $\beta$ are constants determined by fitting the data. The method expressed in Eq. (A18) is equivalent to the Langley method of obtained optical thickness with the only difference the weak dependence of $B$ on sun angle. Such dependence is necessary to include because the diffuse radiation arriving at the surface is weakly dependent upon $\mu_{0}$.

Following the procedure outlined for the real data exactly but including the subscript $\mathrm{p}$ to indicate "proxy" and changing the conditional distributions (Eq. A6) with the marginal distribution (Eq. A2), we can finally write for the proxy global radiation

$S_{\mathrm{p} k}=S_{\mathrm{p}, c_{0} k}\left(1-c_{k}\right)+c_{k} S_{\mathrm{p}, \text { cloud }, k}$,

where $S_{\mathrm{p}, \text { cloud, } k}$ is obtained from an equation identical to Eq. (A9) with $S_{\mathrm{cb}, k}$ replaced by $S_{\mathrm{p}, \mathrm{cb}, k}$. Note, however, that the rest terms $R_{1}$ and $R_{2}$ have vanished in the proxy formulation. The reason is that the conditional distributions have been replaced by the marginal distribution of cosine of solar zenith angles, which is independent of cloud cover fraction and time. Therefore the marginal distributions in the rest term are all identical and thus will cancel exactly. Equation (A20) is represented in the main text as Eq. (1).

Equation (A19) expresses the dependence of atmospheric optical thickness on $\mu_{0}$. Regression fits using Eq. (A19) carry uncertainties into the parameter $B$ and through Eq. (A18) into parameter $G$ and into Eq. (A20). For clear-sky the scatter is small but for skies under (partly) cloudy skies the scatter is larger. The standard $1 \sigma$ uncertainty associated with the clear-sky proxy computed in Eq. (A20) is 2-3\%, increasing to $8-9 \%$ for high okta values.

The year-to-year determination of proxies in Eq. (A20) is used in this paper as it will yield more stable results than the determination of "true" averages. The fitted functions $G$ in Eq. (A18) are smooth, monotonic increasing functions for all okta values. Their use together with the marginal distribution (i.e. all 8760 or 8784 ) of zenith angles to compute the proxy will avoid all seasonal, yearly or multi-year variations that are inherent in the application of the distribution $f_{k}\left(\mu_{0 i} \mid c_{j}\right)$ for which the yearly variable numbers of $\mu_{0 i}$ values necessary to compute the conditionally sampled data are used. Therefore, the computed trends of proxies will reflect the yearly changing transmission through the atmosphere rather than the more spurious effects of random or multi-year seasonal variability in radiation at various cloud fractions.

Note finally that $S_{k} \neq S_{\mathrm{p} k}$ as the proxy analysis is based on an evaluation of proxy fluxes, not of the "real" fluxes. In the analysis to be performed, however, differences between them turned out to be less than $5 \%$ (see Fig. 4 of the main text).

\section{A3 Analysis of trend}

Once a time series of proxy radiation values is obtained it is possible to compute trends. As explained in the previous section, trends in the observed time series of clear-sky and cloudy-sky radiation are not very useful due to the year-toyear variability. However, trends in the proxy radiation time series do not suffer from such noise and thus can yield meaningful results. A single equation will be derived for the trend in all-sky proxy radiation, from which it emerges that such a trend is the result of three components: (a) a trend in fractional cloudiness, (b) a trend in clear-sky radiation and (c) a trend in radiation at cloud base.

To derive trends from the yearly-average (proxy) data we write

$$
\begin{gathered}
c_{k}=\bar{c}+c_{k}^{\prime}, S_{\mathrm{p}, c_{0}, k}=\overline{S_{\mathrm{p}, c_{0}}}+S_{\mathrm{p}, c_{0}, k}^{\prime}, S_{\mathrm{p}}\left(y_{k}\right)=\overline{S_{\mathrm{p}}}+S_{\mathrm{p}}^{\prime}\left(y_{k}\right), \\
S_{\mathrm{p}, \text { cloud }, k}=\overline{S_{\mathrm{p}, \text { cloud }}}+S_{\mathrm{p}, \text { cloud }, k}^{\prime} .
\end{gathered}
$$

Here the bar represents an average over 5 decades of the yearly averages, and the primed variables are the yearly deviations from the averages over the 5 decades under analysis. Inserting into Eq. (A20) yields

$$
\begin{aligned}
S_{\mathrm{p} k} & =\overline{S_{\mathrm{p}}}+S_{\mathrm{p} k}^{\prime}=\left(1-\bar{c}-c_{k}^{\prime}\right)\left(\overline{S_{\mathrm{p}, c_{0}}}+S_{\mathrm{p}, c_{0} k}^{\prime}\right) \\
& +\left(\bar{c}+c_{k}^{\prime}\right)\left(\overline{S_{\mathrm{p}, \text { cloud }}}+S_{\mathrm{p}, \text { cloud }, k}^{\prime}\right) .
\end{aligned}
$$

Defining $\overline{S_{\mathrm{p}}}=(1-\bar{c}) \overline{S_{\mathrm{p}, c_{0}}}+\bar{c} \overline{S_{\mathrm{p}, \text { cloud }}}$ and collecting terms yields

$$
\begin{aligned}
S_{k}^{\prime} & =c_{k}^{\prime}\left(\overline{S_{\mathrm{p}, \text { cloud }}}-\overline{S_{\mathrm{p}, c_{0}}}\right)+(1-\bar{c}) S_{\mathrm{p}, c_{0} k}^{\prime}+\bar{c} S_{\mathrm{p}, \text { cloud }, k}^{\prime} \\
& +c_{k}^{\prime}\left(S_{\text {cloud }, k}^{\prime}-S_{\mathrm{p}, c_{0} k}^{\prime}\right) .
\end{aligned}
$$

Equation (A23) can be used for trend analysis and is represented in the main text as Eq. (3). 
The implications of this expression are quite important. Equation (A23) demonstrates that the trend in all-sky radiation is not a simple summation of trends in clear-sky and cloudy-sky trends, which would perhaps be an intuitive notion when seeking to explain the observed trend in all-sky radiation. Equation (A23) demonstrates that (a) the trends in clear-sky and cloud-base radiation need to be weighted by their fractional occurrence in the atmosphere and that (b) there is a third term constituting the trend in fractional cloudiness scaled by the difference in average cloud-base and clear-sky radiation. Furthermore, the additional fourth term, which is shown to be negligible in the current analysis, may not always be small when there are significant cross correlations between the perturbations. 
Competing interests. The authors declare that they have no conflict of interest.

Acknowledgements. We acknowledge the use of EUMETSAT's CMSAF cloud climatology data sets. We much appreciate discussions with Jan Fokke Meirink, who made us aware of the EUMETSAT data set and who instructed us on its use in this analysis. We also appreciate discussion with Wiel Wauben about the break analysis.

Edited by: Stelios Kazadzis

Reviewed by: two anonymous referees

\section{References}

Albrecht, B. A.: Aerosols, cloud microphysics and fractional cloudiness, Science, 245, 1227-1230, 1989.

Alexanderson, H.: A homogeneity test applied to precipitation data, J. Climate, 6, 661-675, 1986

Augustine, J. A. and Dutton, E. G.: Variability of the surface radiation budget over the United States from 1996 through 2011 from high-quality measurements, J. Geophys. Res., 118, 43-53, https://doi.org/10.1029/2012JD018551, 2010.

Boers, R. and Mitchell, R. M.: Absorption feedback in stratocumulus cloud: Influence on cloud top albedo, Tellus, 46A, 229-241, 1994.

Boers, R., de Haij, M. J., Wauben, W. M. F., Baltink, H. K., van Ulft, L. H., Savenije, M., and Long, C. N.: Optimized fractional cloudiness determination from five ground-based remote sensing techniques, J. Geophys. Res., 115, D24116, https://doi.org/10.1029/2010JD014661, 2010.

Boers, R., van Weele, M., van Meijgaard, E., Savenije, M., Siebesma, A. P., Bosveld, F., and Stammes, P.: Observations and projections of visibility and aerosol optical thickness (1956$2100)$ in the Netherlands: Impacts of time-varying aerosol composition and hygroscopicity, Environ. Res. Lett., 10, 015003, https://doi.org/10.1088/1748-9326/10/1/015003, 2015.

Chiacchio, M. and Wild, M.: Influence of NAO and clouds on long-term seasonal variations of surface solar radiation in Europe, J. Geophys. Res., 115, D00D22, https://doi.org/10.1029/2009JD012182, 2010.

Dee, D. P., Uppala, S. M., Simmons, A. J., Berrisford, P., Poli, P., Kobayashi, S., Andrae, U., Balmaseda, M. A., Balsamo, G., Bauer, P., Bechtold, P., Beljaars, A. C. M., van de Berg, L., Bidlot, J., Bormann, N., Delsol, C., Dragani, R., Fuentes, M., Geer, A. J., Haimberger, L., Healy, S. B., Hersbach, H., Holm, E. V., Isaksen, L., Kallberg, P., Kohler, M., Matricardi, M., McNallya, A. P., Monge-Sanz, B. M., Morcrette, J.-J., Park, B.-K., Peubey, C., de Rosnay, P., Tavolato, C., Thepaut, J.-N., and Vitart, F.: The ERA-Interim reanalysis: configuration and performance of the data assimilation system, Q. J. Roy. Meteor. Soc., 137, 553-597, 2010.

Eltermann, L.: Relationships between vertical attenuation and surface meteorological range, Appl. Optics., 9, 1804-1810, https://doi.org/10.1364/AO.9.001804, 1970.

Gan, C.-M., Pleim, J., Mathur, R., Hogrefe, C., Long, C. N., Xing, J., Roselle, S., and Wei, C.: Assessment of the ef- fect of air pollution controls on trends in shortwave radiation over the United States from 1995 through 2010 from multiple observation networks, Atmos. Chem. Phys., 14, 1701-1715, https://doi.org/10.5194/acp-14-1701-2014, 2014.

Gultepe, I. and Isaac, G. A.: The relationship between cloud droplet and aerosol number concentration for climate models, Int. J. Climate, 16, 941-946, 1995.

IPCC: Climate Change 2013: The Physical Science Basis. Contribution of Working Group I to the Fifth Assessment Report of the Intergovernmental Panel on Climate Change, edited by: Stocker, T. F., Qin, D., Plattner, G.-K., Tignor, M., Allen, S. K., Boschung, J., Nauels, A., Xia, Y., Bex, V., and Midgley, P. M., Cambridge University Press, Cambridge, United Kingdom and New York, NY, USA, 1535 pp., https://doi.org/10.1017/CBO9781107415324, 2013.

Jones, A., Roberts, D. L., and Slingo, A.: A climate model study of indirect radiative forcing by anthropogenic sulphate aerosols, Nature, 370, 450-453, 1994.

Karlsson, K.-G., Anttila, K., Trentmann, J., Stengel, M., Fokke Meirink, J., Devasthale, A., Hanschmann, T., Kothe, S., Jääskeläinen, E., Sedlar, J., Benas, N., van Zadelhoff, G.J., Schlundt, C., Stein, D., Finkensieper, S., Håkansson, N., and Hollmann, R.: CLARA-A2: the second edition of the CM SAF cloud and radiation data record from 34 years of global AVHRR data, Atmos. Chem. Phys., 17, 5809-5828, https://doi.org/10.5194/acp-17-5809-2017, 2017.

Kendall, M. G.: Rank Correlation Methods, 4th Edn., Charles Griffin, London, 1975.

Kriebel, K. T.: On the determination of the atmospheric optical depth by measurements of the meteorological range, Beitr. Phys. Atmos., 51, p. 330, 1978.

Li, H., Sheffield, J., and Wood, E. F.: Bias correction of monthly precipitation and temperature fields from Intergovernmental Panel on Climate Change AR4 models using equidistant quantile matching, J. Geophys. Res., 115, D10101, https://doi.org/10.1029/2009JD012882, 2010.

Liepert, B. G.: Recent changes in solar radiation under cloudy conditions in Germany, Int. J. Climatol., 17, 1581-1593, 1997.

Liepert, B. G.: Observed reductions of surface solar radiation at sites in the United States and worldwide from 1961 to 1990, Geophys. Res. Lett., 29, 1421, https://doi.org/10.1029/2002GL014910, 2002.

Liepert, B. and Kukla, G.: Decline in solar radiation with increased horizontal visibility in Germany between 1964 and 1990, J. Climate, 10, 2391-2401, 1997.

Liepert, B. and Tegen, I.: Multidecadal solar radiation trends in the United States and Germany and direct tropospheric aerosol forcing J. Geophys. Res., 107, 4153, https://doi.org/10.1029/2001JD000760, 2002.

Long, C. N. and Ackerman, T. P.: Identification of clear skies from broadband pyranometer measurements and calculation of downwelling shortwave cloud effects, J. Geophys. Res., 105, 1560915626, 2000.

Long, C. N., Dutton, E. G., Augustine, J. A., Wiscombe, W., Wild, M., McFarlane, S. A., and Flynn, C. J.: Significant decadal brightening of downwelling shortwave in the continental United States, J. Geophys. Res., 114, D00D06, https://doi.org/10.1029/2008JD011263, 2009. 
Manara, V., Brunetti, M., Celozzi, A., Maugeri, M., SanchezLorenzo, A., and Wild, M.: Detection of dimming/brightening in Italy from homogenized all-sky and clear-sky surface solar radiation records and underlying causes (1959-2013), Atmos. Chem. Phys., 16, 11145-11161, https://doi.org/10.5194/acp-16-111452016, 2016.

Mateos, D., Sanchez-Lorenzo, A., Antón, M., Cachorro, V. E., Calbó, J., Costa, M. J., Torres, B., and Wild, M.: Quantifying the respective roles of aerosols and clouds in the strong brightening since the early 2000s over the Iberian Peninsula, J. Geophys. Res., 119, 10382-10393, https://doi.org/10.1002/2014JD022076, 2014.

Norris, J. R.: Multidecadal changes in near-global cloud cover and estimated cloud cover radiative forcing, J. Geophys. Res., 110, D08206, https://doi.org/10.1029/2004JD005600, 2005.

Norris, J. R. and Wild, M.: Trends in aerosol radiative effects over Europe inferred from observed cloud cover, solar "dimming," and solar "brightening”, J. Geophys. Res., 112, D08214, https://doi.org/10.1029/2006JD007794, 2007.

Ohvril, H., Teral, H., Neiman, L., Kannel, M., Uustare, M., Tee, M., Russak, V., Okulov, O., Joeveer, A., Kallis, A., Ohvril, T., Terez, E., Terez, G., Gushchin, G., Abakumova, G., Gorbarenko, E., Tsvetkov, A., and Laulainen, N.: Global dimming and brightening versus atmospheric column transparency, Europe, 1906-2007, J. Geophys. Res., 114, D00D12, https://doi.org/10.1029/2008JD010644, 2009.

Parding, K., Olseth, J. A., Dagestadt, K. F., and Liepert, B. G.: Decadal variability of clouds, solar radiation and temperature at a high-latitude coastal site in Norway, Tellus B, 66, 1-17, 2014.

Peterson, J. T. and Fee, C. J.: Visibility-atmospheric turbidity dependence at Raleigh, North Carolina, Atmos. Environ., 15, 25612563, 1981.

Philipona, R., Behrens, K., and Ruckstuhl, C.: How declining aerosols and rising greenhouse gases forced rapid warming in Europe since the 1980s, Geophys. Res. Lett., 36, L02806, https://doi.org/10.1029/2008GL036350, 2009.

Romanou, A., Liepert, B., Schmidt, G. A., Rossow, W. B., Ruedy, R. A., and Zhang, Y.: 20th century changes in surface solar irradiance in simulations and observations, Geophys. Research Lett. 34, L057113, https://doi.org/10.1029/2006GL028356, 2007.

Ruckstuhl, C. and Norris, J. R.: How do aerosol histories affect solar "dimming" and "brightening" over Europe?: IPCC-AR4 models versus observations, J. Geophys. Res., 114, D00D04, https://doi.org/10.1029/2008JD011066, 2009.

Ruckstuhl, C., Philipona, R., Behrens, K., Collaud Coen, M., Durr, B., Heimo, A., Matzler, C., Nyeki, S., Ohmura, A., Vuilleumier, L., Weller, M., Wehrli, C., and Zelenka, A.: Aerosol and cloud effects on solar brightening and the recent rapid warming, Geophys. Res. Lett, 35, L12708, https://doi.org/10.1029/2008GL034228, 2008.
Ruckstuhl, C., Norris, J. R., and Philipona, R.: Is there evidence for an aerosol indirect effect during the recent aerosol optical depth decline in Europe?, J. Geophys. Res., 115, D04204, https://doi.org/10.1029/2009JD012867, 2010.

Russak, V.: Changes in solar radiation and their influence on temperature trend in Estonia (1955-2007), J. Geophys. Res., 114, D00D01, https://doi.org/10.1029/2008JD010613, 2009.

Sanchez-Lorenzo, A., Wild, M., Brunetti, M., Guijarro, J. A., Hakuba, M. Z., Calbó, J., Mystakidis, S., and Bartok, B.: Reassessment and update of long-term trends in downward surface shortwave radiation over Europe (1939-2012), J. Geophys. Res.-Atmos., 120, 9555-9569, https://doi.org/10.1002/2015JD023321, 2015.

Stjern, C. W., Kristjansson, J. E., and Hansen, A. W.: Global dimming and global brightening - an analysis of surface radiation and cloud cover data in northern Europe, Int. J. Climatol., 29, 643-653, 2009.

Turnock, S. T., Spracklen, D. V., Carslaw, K. S., Mann, G. W., Woodhouse, M. T., Forster, P. M., Haywood, J., Johnson, C. E., Dalvi, M., Bellouin, N., and Sanchez-Lorenzo, A.: Modelled and observed changes in aerosols and surface solar radiation over Europe between 1960 and 2009, Atmos. Chem. Phys., 15, 9477 9500, https://doi.org/10.5194/acp-15-9477-2015, 2015.

Twomey, S.: The influence of pollution on the shortwave albedo of clouds, J. Atmos. Sci., 34, 1149-1152, https://doi.org/10.1175/1520-0469, 1977.

Wang, K. C., Dickinson, R. E., and Liang, S. L.: Clear-sky visibility has decrease over land globally from 1973 to 2007, Science, 323 , 1468-1470, https://doi.org/10.1126/science.1167549, 2009.

Wild, M.: Global dimming and brightening: A review, J. Geophys. Res., 114, D00D16, https://doi.org/10.1029/2008JD011470, 2009.

Wild, M.: Introduction to special section on Global Dimming and Brightening, J. Geophys. Res., 115, D00D00, https://doi.org/10.1029/2009JD012841, 2010.

Wild, M., Gilgen, H., Roesch, A., Ohmura, A., Long, C. N., Dutton, E. G., Forgan, B., Kallis, A., Russak, V., and Tsvetkov, A.: From Dimming to Brightening: Decadal Changes in Solar Radiation at Earth's surface, Science, 308, 847, https://doi.org/10.1126/science.1103215, 2005.

World Meteorological Organization (WMO), WMO guide to meteorological instruments and methods of observation, 7th Edn., WMO-No. 8, Geneva, Switzerland, 2008.

Wu, J., Luo, J., Zhang, L., Xia, L., Zhao, D., and Tang, J.: Improvement of aerosol optical depth retrieval using visibility data in China during the past 50 years, J. Geophys. Res., 119, 13370 13387, https://doi.org/10.1002/2014JD021550, 2014. 